\title{
RACIONALISMO Y EMOTIVISMO EN PERSPECTIVA NEUROÉTICA
}

\author{
PEDRO JESÚS PÉREZ ZAFRILLA
}

Universitat de València

\begin{abstract}
RESUMEN. El desarrollo de la neuroética ha tendido a privilegiar el papel de la emoción en detrimento del razonamiento en la deliberación moral. En esta comunicación deseo contraponer dos modelos de deliberación moral que se han articulado desde la neuroética: uno de corte emotivista, desarrollado por Haidt y Lakoff y otro, pretendidamente racionalista, elaborado recientemente por Hugo Mercier. Mi objetivo es determinar si Mercier lleva realmente a cabo una rehabilitación del razonamiento en la neuroética o si, por el contrario, su planteamiento es deudor del de los enfoques emotivistas.
\end{abstract}

PALABRAS CLAVE: neuroética, Lakoff, Haidt, Mercier, deliberación.

\section{Rationalism and emotivism from a neuroethic approach}

ABSTRACT. The development of neuroethics has used to privilege the role of emotion in contrast to reasoning in moral deliberation. My aim in this paper to oppose two models of moral deliberation articulated from neuroethics: the emotivist one, developed by Haidt and Lakoff; and the rationalist one, elaborated by Hugo Mercier. My aim is to stablish if Mercier rehabilitates reasoning in neuroethics or if his approach is an emotivist one too.

KEY WORDS: neuroethics, Lakoff, Haidt, Mercier, deliberation.

\section{INTRODUCCIÓN}

A lo largo de la historia de la filosofía, pero de un modo significativo desde la Modernidad y la Ilustración, ha imperado en el ámbito del pensamiento un modelo de racionalidad concreto. La razón es entendida como una facultad de pensamiento consciente, sosegado, lógico y no emocional. Por el contrario, la emoción, se entiende, perturba la objetividad del razonamiento ${ }^{1}$.

Sin embargo, este modelo dicotómico entre razón y pasión ha sido puesto en cuestionamiento recientemente desde los planteamientos de la neuroética. Los nuevos descubrimientos neurocientíficos revelan que las emociones no son un elemento ajeno a la deliberación. Es más, en realidad, sin el componente emocional no sería posible tomar decisiones ni hacer juicios racionales. Así lo ponen de manifiesto, por ejemplo, los estudios realizados por Antonio Damasio con enfermos de daño cerebral adquirido ${ }^{2}$.

1 Maíz, R., «La hazaña de la razón: la exclusión fundacional de las emociones en la teoría política moderna», en: Revista de Estudios Políticos, vol.149, 2010, p. 14.

2 Damasio, A., El error de Descartes, Crítica, Barcelona, 1994. 
Pero también este reconocimiento de las emociones en la deliberación no está exento de problemas. Neurocientíficos como Haidt, Kahneman, Hauser o Greene pretenden reivindicar el papel de las emociones a costa de devaluar el papel del razonamiento. En esta comunicación pretendemos analizar el modo en que desde la neuroética se entiende esa primacía de las emociones sobre el razonamiento y en qué medida ello pone en crisis los procesos deliberativos. Para ello contrapondremos un modelo de corte antirracionalista, representado por Lakoff y Haidt frente a otro que pretende reivindicar el papel del razonamiento desde la neuroética: la teoría argumentativa del razonamiento de Hugo Mercier.

\section{LA DELIBERACIÓN}

Según Lakoff y Haidt, el modelo racionalista de acuerdo al cual la deliberación se asienta en un intercambio de argumentos e información que conduce al acuerdo en torno al mejor argumento, se basa en un error. La causa de ello se encontrará, para Lakoff y Haidt en que el razonamiento ni se asienta sobre la reflexión y la evaluación de las evidencias presentes en el caso ni tampoco está dirigido al convencimiento racional. Por el contrario, el razonamiento consiste en una elaboración sesgada y una exposición de razones post hoc acordes con la actitud previa del sujeto sobre el asunto ${ }^{3}$. De esta manera la deliberación quedará reducida a un choque de razones post hoc que meramente apoyan la tesis hacia la que cada uno tiene una actitud positiva.

Pero si la deliberación parte de un choque entre actitudes, el modo más inteligente de conducirla hacia el acuerdo será tratar de transformar la actitud del interlocutor para que adopte una similar a la propia. Ello se logrará gracias al recurso a la metáfora, la evocación de imágenes y otros elementos retóricos capaces de crear nuevas intuiciones en el interlocutor que le hagan percibir o «enmarcar» el problema de un modo distinto ${ }^{4}$.

Las metáforas son para Lakoff y Haidt el elemento clave que articula la deliberación. Constituyen el recurso para llegar a las fuentes intuitivas e inconscientes de los juicios morales. Esto es así porque para ellos nuestra cognición se articula sobre unos marcos mentales forjados en nuestro cerebro por la activación de las sinapsis cerebrales. Estos marcos conectan de forma inconsciente los estímulos que recibimos de la realidad (es decir, las metáforas) con emociones (de aprobación o rechazo) y pensamientos determinados dentro de una narrativa ${ }^{5}$. De esta forma,

3 HAIDT, J., "The emotional dog and its rational tail. A social intuitionist approach to moral judgment», en: Psychological Review, vol. 108, 2001, p. 823; Mercier, H. y SPerber, D., "Why do humans reason? Arguments for an argumentative theory?», en: Behavioural and brain sciences, vol. 34, 2011, p. 67.

4 Haidt, J. y BJorklund, F., «Social Intuitionists answer six questions about moral psychology», en: Sinnott-Armstrong, W. (ed.), Moral Psychology, vol. 2, Massachusetts: The MIT Press, 2007, p. 192; НAIDT, J., The righteous mind, Why good people are divided by politics and religion, Pantheon Books, New York, 2012, p. 47.

5 Lakoff, G., The political mind, A cognitive scientist guide to your brain and its politics, Penguin Books, New York, 2008, p. 93. 
toda la información y las evidencias que contradicen el marco son ignoradas. Por ese motivo la argumentación racional no sirve para hacer a las personas cambiar de opinión ${ }^{6}$. Serán, por el contrario, las metáforas el recurso más eficaz. Mediante su repetición reiterada, las metáforas activan en el oyente la conexión sináptica hasta formar un circuito permanente. Entonces, con sólo escuchar la palabra, se activará en el oyente el marco de pensamiento asociado a él. Es entonces cuando se logrará imponer sobre el público un marco de pensamiento para hacer así ese marco hegemónico en el discurso frente al marco contrario. La deliberación queda así reducida a un mecanismo de manipulación emocional.

\section{La Teoría Argumentativa del Razonamiento}

Otra propuesta actual que analiza la argumentación desde la neuroética es la denominada «Teoría argumentativa del Razonamiento» (en adelante TAR), defendida por autores como Hugo Mercier y Dann Sperber.

La principal diferencia de esta teoría con el planteamiento emotivista de Haidt y Lakoff está en que para la TAR el razonamiento se entiende de un modo distinto a como se entiende en la concepción dual de la cognición humana. Según la TAR, la función del razonamiento no es la formación de juicios de forma privada. Por el contrario, su función es argumentativa en un contexto interpersonal. Es decir, el razonamiento sería una facultad desarrollada evolutivamente para facilitar la adaptación de los sujetos en los contextos interpersonales. El objetivo del razonamiento sería el de permitir al sujeto mantener su reputación ante los demás mediante el intercambio de información con sus semejantes para que éstos tengan una buena imagen de él ${ }^{7}$.

El razonamiento según Mercier se define como «el mecanismo cognitivo específico que trata de recopilar y evaluar razones, de tal forma que los individuos puedan convencer a otras personas y evaluar sus argumentos ${ }^{8}$. Es decir, consta de dos procesos bien diferenciados: por un lado, evaluar las razones del interlocutor para quedarse con la información relevante y, por otro lado, está la función de buscar y presentar argumentos que apoyen nuestra posición.

Pero para que el razonamiento pueda cumplir su función adaptativa debe desarrollarse en un contexto adecuado, caracterizado por dos elementos: el razonamiento debe desarrollarse en un marco de discrepancia sobre el asunto a tratar y debe producirse una evaluación de los argumentos del oponente. Estas condiciones son importantes, ya que el razonamiento realizado de forma privada o entre sujetos afines estará sometido al sesgo cognitivo de confirmación ${ }^{9}$. En cambio, cuando

\footnotetext{
6 Lakoff, G., The political mind, p. 8.

7 Mercier, H., y SPERBER, D., «Why do humans reason? Arguments for an argumentative theory», p. 60.

8 Mercier, H., y Landemore, H., «Talking it out with others vs. deliberation within and the law of group polarization: Some implications of the argumentative theory of reasoning for reasoning for deliberative democracy», en: Análise Social, vol. 205, 2012, p. 914.

9 Lord, C. G., Ross, L y Lepper, M., «Biased Assimilation and Attitude Polarization: The Effects of Prior Theories on Subsequently Considered Evidence», en: Journal of Personality and Social Psychology, vol. 37, 1979, p. 2099.
} 
la persona reflexiona en privado propiamente no evalúa evidencias, sino que crea argumentos acordes a su actitud sobre el asunto. De la misma manera, al razonar entre personas afines no hay posibilidad de reconocer si las propias tesis son erróneas. Para ello es necesario razonar con alguien que discrepe de nuestra opinión. De ahí que la TAR insista tanto en que el razonamiento se desarrolle en un contexto de desacuerdo.

En esta situación de desacuerdo cada cual aporta razones favorables a su posición y evalúa las del contrario. En ese zig-zag argumentativo cada sujeto se dejará convencer cuando reconozca racionalmente que las razones de su interlocutor son superiores a las que él posee. El resultado de ese proceso recíproco de razonamiento será la toma de la mejor decisión ${ }^{10}$. De esta forma, de acuerdo a la TAR, el razonamiento ejercido en esas condiciones de desacuerdo constituye un genuino proceso deliberativo tal y como es entendido desde la democracia deliberativa.

\section{Conclusiones}

En consecuencia, parece que la TAR apuesta por una revitalización del razonamiento desde la neuroética, al menos cuando éste se ejerce en un marco interpersonal, frente a las tesis de Lakoff y Haidt quienes reducían el proceso deliberativo a la manipulación emocional.

Sin embargo, esto no es del todo así. En realidad, el modelo de la TAR no cumpliría su objetivo de articular verdaderos procesos deliberativos con valor epistémico ya que su concepción del razonamiento se enfrenta a diversos problemas. Señalaré únicamente uno, relativo a que la TAR no da cuenta debidamente de la motivación de los sujetos en la deliberación. En consonancia con otros autores de la neuroética, la motivación que Mercier atribuye a los sujetos es mantener la reputación dentro del grupo ${ }^{11}$. El sujeto ofrecerá los argumentos apropiados no para defender lo que considera justo, sino para que los demás tengan una imagen favorable de él. Porque una imagen negativa de uno podría derivar en el rechazo por parte de los demás. Por ello, de acuerdo al planteamiento de Mercier, el proceso argumentativo siempre estaría supeditado al cálculo estratégico sobre lo que puede ser dicho y lo que no para salvaguardar la reputación.

No obstante, esta motivación está muy alejada de aquella que poseen realmente los sujetos en los procesos deliberativos según muestran los autores de la democracia deliberativa. Como muestra Cohen, quien argumenta en los procesos deliberativos lo hace para defender algo que consideran justo con independencia de sus intereses egoístas ${ }^{12}$. La deliberación es así una forma de racionalidad comunicativa dirigida al consenso. En cambio, Mercier presenta una forma de argumentación

10 Mercier, H., «Reasoning is for arguing: Understanding the Success and Failures of Deliberation», en: Political Psychology, vol. 33, p. 2012, p. 245.

11 Mercier, H., "What good is moral reasoning?», en: Mind and Society, vol. 10, 2011, p.141. Cfr. Alexander, R., The biology of moral systems, Aldine de Gruyter, New York, 1987, p.85; TrIVERS, R. L., "The evolution of reciprocal altruism», en: The Quarter Review of Biology, vol. 46, 1971, pp. 35-57.

12 Cohen, J., «An epistemic conception of democracy», en: Ethics, vol. 97, 1986, pp. 26-38. 
propia de una racionalidad estratégica guiada por el interés de mantener la supervivencia.

De esta forma, podemos concluir que el intento de Mercier de rehabilitar el razonamiento desde planteamientos neurocientíficos ha resultado en fracaso. El análisis de la argumentación desde la perspectiva neurocientífica es claramente reduccionista. Por un lado, Lakoff y Haidt reducen la deliberación a la mera persuasión emocional. Pero también la TAR reduce el razonamiento a un mecanismo cognitivo orientado a mantener la supervivencia en el grupo. En conclusión, los autores de la neurociencia son incapaces de lograr un equilibrio entre razón y pasión en el proceso deliberativo.

[Artículo aprobado para publicación en diciembre de 2016] 